\title{
Research possibility of application of non-destructive testing method based on the Barkhausen effect for the control of heat exchange equipment, exposed to im-pulse pressure
}

\author{
Potapov V.V. ${ }^{1}$, Lopatin M.V. ${ }^{2}$, Lopatina L.I. ${ }^{2}$, Chebotnyagin * ${ }^{*} . M .^{1}$ \\ ${ }^{1}$ Irkutsk National Research Technical University Lermontov str.83,Irkutsk, Russia \\ ${ }^{2}$ Irkutsk State Transport University Chernyshevsky st. 15, Irkutsk Russia
}

\begin{abstract}
The article deals with the issues of ensuring the reliability of operation and methods for evaluation of connections (tube attachment points in tube sheets) of heat exchangers used in various industries. It is estimated the applicability of the control method based on the Barkhausen effect to check the place of tube fastening in tube sheets. Installations are considered as heat exchangers in which the connection is derive pipe with tube sheets is obtained by using impulsed pressure sources.
\end{abstract}

\section{Introduction}

Heat exchanger is one of the most common elements of power, utility and technological installations. Any transformation of energy from one type to another, as well as the transfer of energy from one apparatus to another, are accompanied by the transfer of some part of all other types of energy into heat [1-8].

Heat exchangers of power plants are large-scale, metal-intensive and expensive equipment, significantly affecting the efficiency and reliability of power plants of all types (TPP, NPP and CS) as a whole.

One of the nodes that determines the reliability of the heat exchanger is the connection of tubes with tube sheets. A promising method is the method of mounting tubes in tube sheets of heat exchangers using impulsed pressure generated by a plasma channel of an electric spark initiated by an electrical explosion of a conductor (EEC). The impulse pressure generated in this way provides a high-speed deformation of the tube wall (with speeds greater than $100 \mathrm{~m} / \mathrm{s}$ ) and causes a joint to collide when its outer surface collides with the inner surface of the tube sheet opening, and if certain conditions are met, welding occurs [8-10].

Impact loads that a tube undergoes when performing a mounting operation in this way, cause strains and internal residual stresses in the thick-ness of the tube wall. When the heat exchanger operates under load, such stresses can cause cracks and lead to a decrease in the strength of the tube structure. The control of the stress-strain state of such steel structures by non-destructive methods allows you to prevent the occurrence of the above undesirable phenomena. [11] In addition, a quick assessment of the residual stresses allows you to adjust the mounting operation.

To control residual stresses in steel structures, the method based on the Barkhausen effect (BE) has found application. The essence of the method is described in detail in [12-18]. However, the possibility of its use to control the pipe attachment points in the tube sheets of heat exchangers has not been evaluated.

The paper discusses the possibility of non-destructive testing of the stress-strain state of steel tubular structures exposed to shock loads (pulsed pressure created by an expanding plasma channel of an electric spark initiated by an EEC, using an BE method..

\section{Experimental researches}

To assess the possibility of applying the method based on the BE to control the place of fastening of the tube in the tube sheet, a series of experiments were performed on samples of steel and aluminum pipes. The pipes were exposed to a pressure impulse created by the expanding spark plasma channel initiated by the EEC. The diagram and general view of the installation for fastening pipes in tube re-grilles, in this case for high-speed deformation of the pipe in the radial direction, are shown in fig. 1.

The deformation of pipe samples using such an installation is as fol-lows. For the experiment, steel tube samples (steel grade 20) with geometrical dimensions were used as a tube sheet element: an outer diameter of 38 $\mathrm{mm}$, a wall thickness of $4 \mathrm{~mm}$, in which aluminum sleeves were fastened with an outer diameter of $28 \mathrm{~mm}$ and a wall thickness of $3 \mathrm{~mm}$. The sleeves contained an electric cartridge, the sketch of which is shown in Fig. 2. In fig. 3 shows a photo of the samples. 

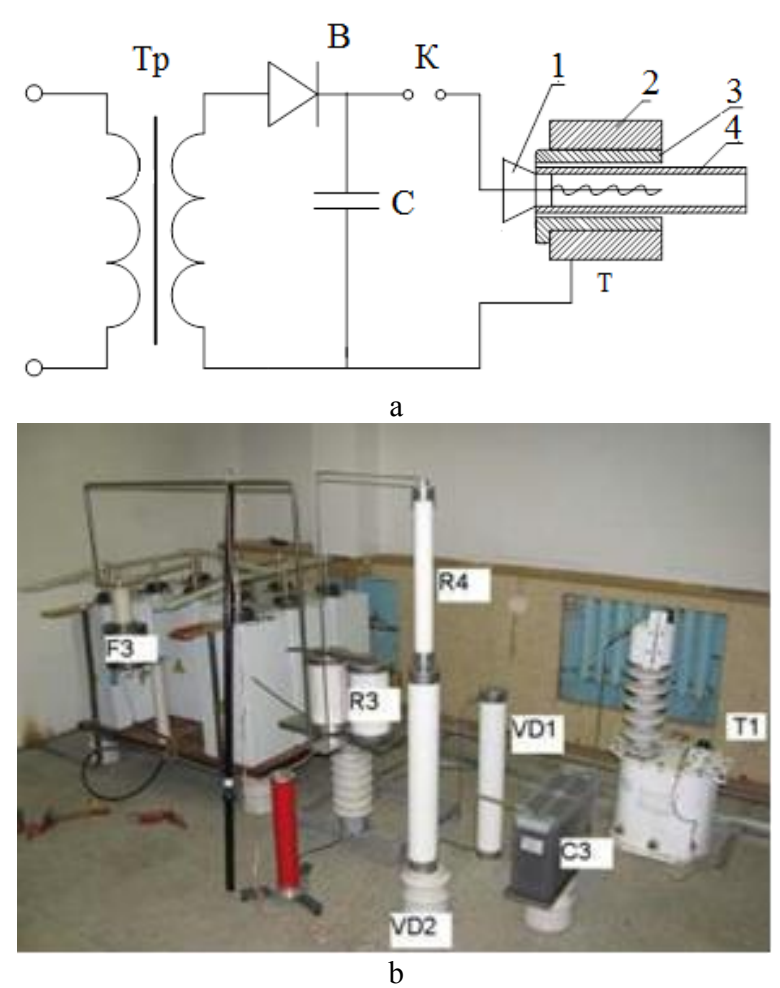

Fig.1. a) Installation diagram: $\mathrm{Tr}$ - high-voltage charging transformer, B - high-voltage rectifier, C - shock capacitance, K - switch (spark discharge), T - technological node; 1 - electric blasting cartridge, 2 - steel tube, 3 - copper tip, 4 - aluminum tube b) Photo of the installation

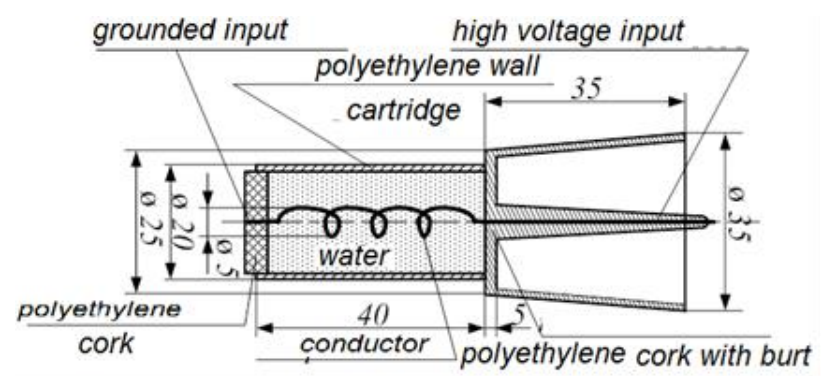

Fig. 2 - Sketch cartridge

Further, the process was as follows. When the battery of electric capacitors is discharged (Fig. 1 a - C) through a thin conductor (not larger than $1 \mathrm{~mm}$ in diameter) of an electrically explosive cartridge 1 (Fig. 1a and Fig. 2), filled with a transmitting medium (water), a current pulse flows with a duration of several microseconds and amplitude up to $100 \mathrm{kA}$. With such parameters of the current pulse, a phenomenon, called the conductor explosion occurs [19-20]. When it explodes in water, a shock wave forms, propagating in a radial direction to the tube wall. The shock wave acts on the pipe wall, which causes its high-speed deformation.

The registration of currents and voltages was carried out using the Rogowski belt and a capacitive voltage divider. A Tektronix DPO3000 oscilloscope was used as a recording instrument. A typical oscillogram of the currents during the initiation of an electric spark of an EEC for generating a pulse pressure for fastening aluminum pipes in steel is shown in Fig. 4.

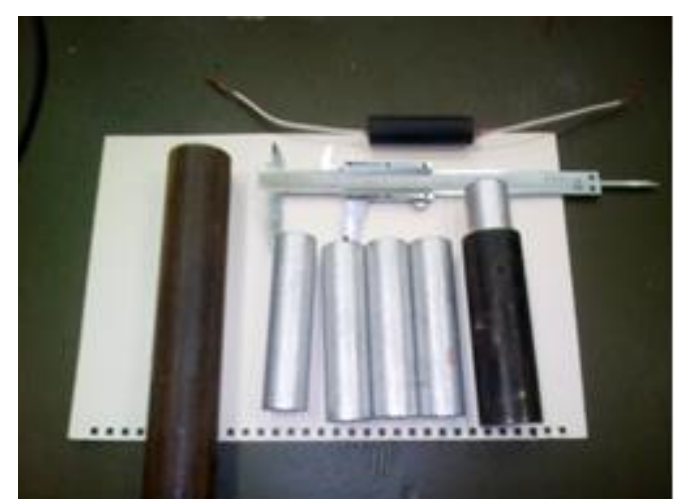

Fig. 3 - Photo samples before pressing

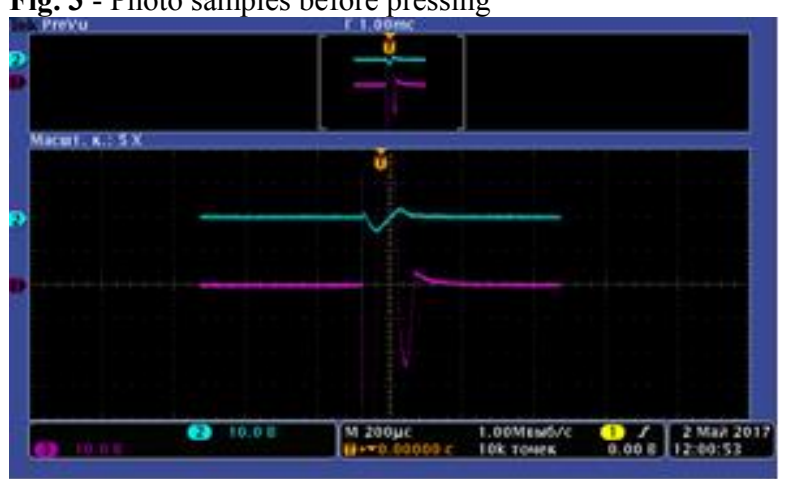

Fig. 4 - Typical oscillogram of current when pressing aluminum tube into steel

According to the results, five series of experiments were performed on 10 samples. During the experiments the charging voltage of the installation was varied $\mathrm{U}_{\mathrm{ch}}=21 \ldots 28 \mathrm{kV}$. With such voltge, the tube was deformed with a maximum increase in the external diameter of the steel pipe to $39.5 \mathrm{~mm}$, a photo of a typical result is shown in Fig. 5. During of experiments from the first to the fourth series, the effect of press fitting of the aluminum tube into a the steel one was observed.

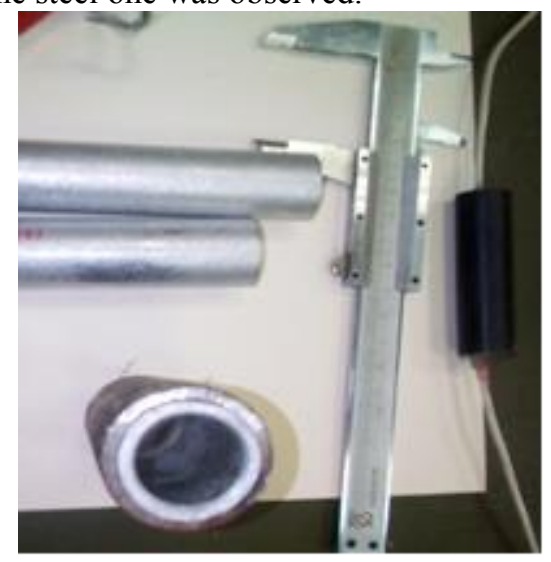

Fig. 5 - Flared aluminum tube in steel pipe

Control of the stress-strain state of pipe samples

Studies of the possibility of monitoring the stressstrain state of the tube samples were carried out on the installation, structural, the scheme of which is shown in fig. 6 .

The block diagram includes a magnetizing system consisting of a winding 6 on a soft magnetic core 4 . The winding 6 is powered by a sinusoidal voltage generator 1 through a power amplifier 2. Current sensor 10 is connected on with a magnetizing coil in series (low-ohmic 
resistor of high-power). The signals of the electromotive force (EMF) from the Barkhausen jumps (BJ) in ferromagnetic sample 11 are recorded by measuring coil 5 of the induction transducer. Since a cylindrical object (pipe) is used as a sample, special inserts in the form of parallelepipeds with a semicylindrical recess of magnetically soft steel were made for its installation on the core 4.

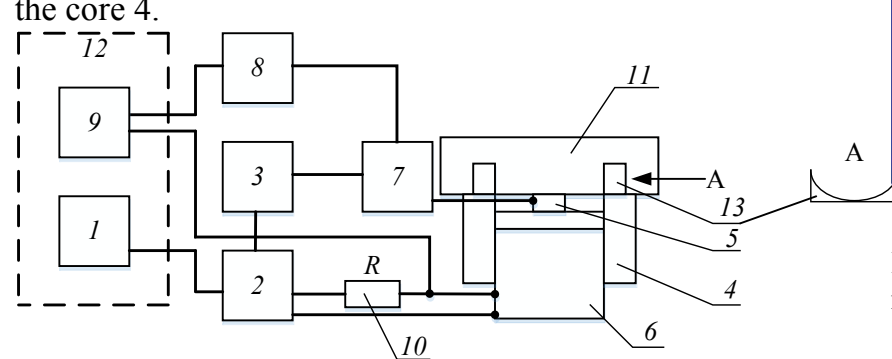

Fig. 6 - General block diagram of the installation: 1- pulse generator; 2 - power amplifier; 3 - power supply; 4 - soft magnetic core; 5 - measuring coil; 6 - magnetizing device winding; 7 - broadband signal amplifier; 8 - output detector; 9 two-channel digital oscillograph; 10 - current sensor; 11 sample; 12 - personal computer system unit; 13 - rectangular parallelepiped with a semi-cylindrical recess of magnesy-soft steel

The EMF signals from the BJ in the measuring coil 5 are amplified by a wideband amplifier 7 , rectified by detector 8, which output is connected to the first channel of the oscilloscope. The second channel of the oscilloscope is connected with current sensor 10, its signal is proportional to the magnetization reversal field.

Thus, the distribution of the EMF signals from the BJ over the magnetization field is displayed on the oscilloscope screen. In this case, it is possible to observe both the output signal of the amplifier 7 and the signal after the detector 8 .

\section{Analysis of experimental studies and results of calculations}

In order to research the opportunities of non-destructive testing of pressing aluminum tubes into steel ones, the dependences of the EMF from BJ on the strain and pressure for the samples performed the experiments series from $\mathrm{N}=1$ to $\mathrm{N}=4$ were obtained. The fifth series of experiments was not considered because of the destruction of the samples. With the help of the installation described above, for each sample from series 1 to 4 , the measurements of EMF from the BJ are made.

Signal recording of the EMF from the BJ was carried out using digital oscilloscope DPO3000. Simultaneously the current of magnetization ( 0,44 Amplitude a, frequency $\mathrm{f}=3 \mathrm{~Hz}$ ) was recorded. Typical waveform is shown in Fig. 7.

The obtained waveforms were processed in the MS Excel program, in which at the first stage the picture similar to the obtained photos from the oscilloscope was reproduced. Typical results of data processing are shown in Fig. 8.

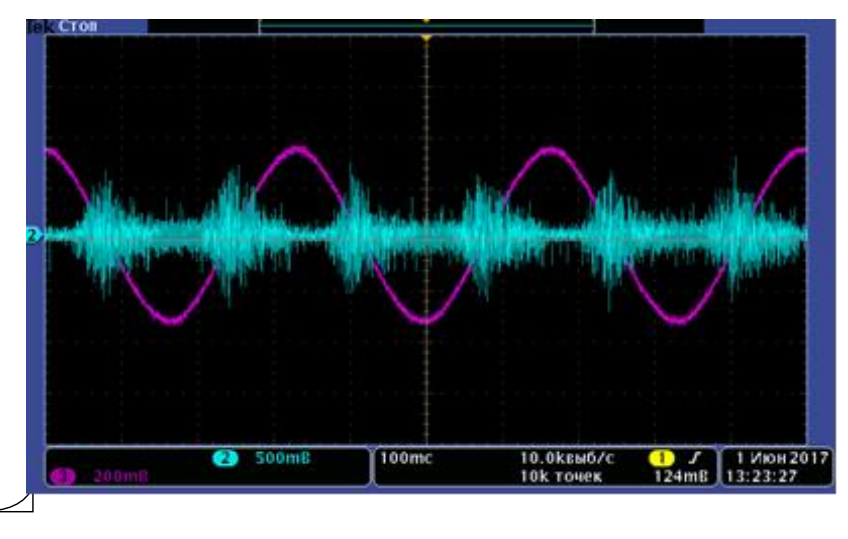

Fig. 7 - Typical oscillogram of the process of magnetization reversal and EMF registration from SB

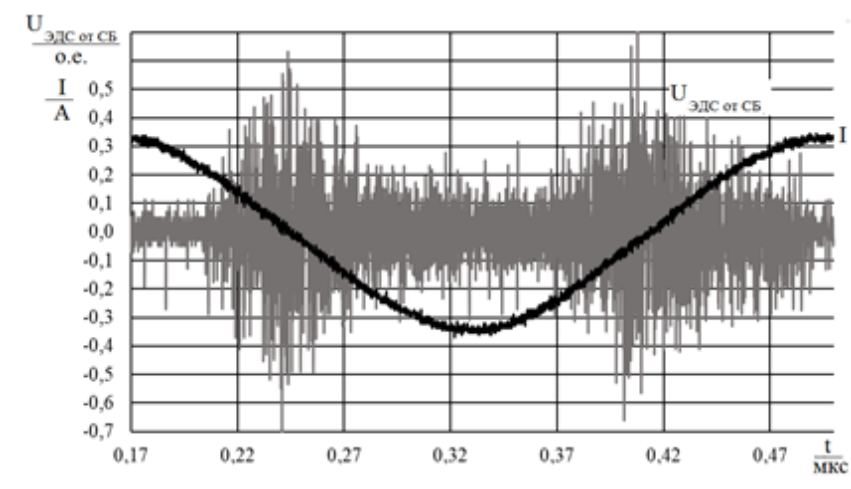

Fig. 8 - reproduced in Excel EMF measurement result FROM $\mathrm{SB}$ and re-magnetization current

As seen in Fig. 7 and 8, the distribution of EMF pulses from the BJ over the half-cycle of alternating magnetization (the period of non-stationary of the process) is a non-stationary random process. In this regard, the further assessment and construction of EMF noise dependences on deformations and pressures should be performed on the amplitudes of the RMS values of EMF from the BJ.

In accordance with [21] RMS (root mean square value) for the signal was determined by the formula

$$
U_{R M S}=\sqrt{\frac{1}{n}\left(U_{1}^{2}+U_{2}^{2} \ldots+U_{i=n}^{2}\right)}
$$

where $\mathrm{n}$ is the number of averaged values; $\mathrm{Ui}$ is the EMF value from the $\mathrm{BJ}$ for the $\mathrm{i}$-th value.

For the calculations of each RMS EMF from the BJ, it is assumed that $n=20$. A typical result of the averaging is shown in Fig. 9. 


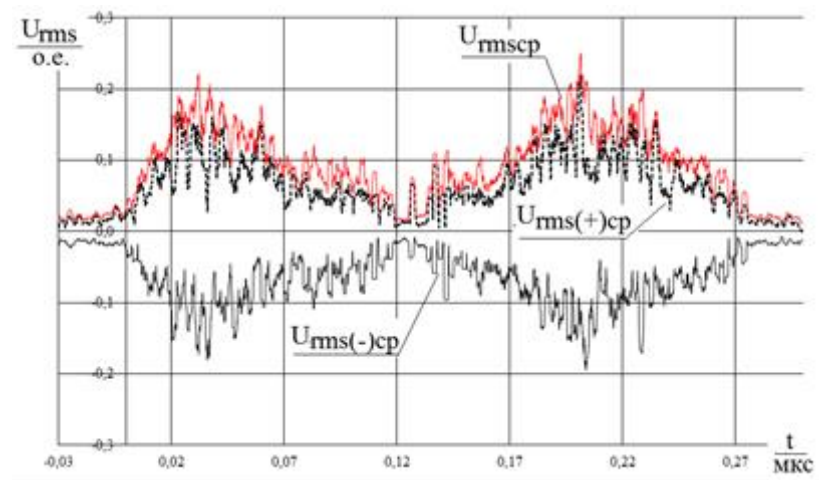

Fig. 9 Distribution of RMS values of EMF from the BJ over the period of re-magnetization of one of the samples of the $n=1$ series

To assess the effect of the impulse pressure generated by the plasma channel of the spark initiated by the EVP on the stress-strain state of the pipe samples, the amplitude of this pressure according to [22] is approximated by the formula

$$
P_{m}=\frac{A}{\cos ^{2}\left(\frac{\pi}{8}\right)} \cdot \frac{U \cdot C^{1 / 4}}{L^{3 / 4}} \cdot \cos ^{2}\left(\frac{\pi}{2 T} \cdot t\right)
$$

Where - the time constant of the pressure wave decay; $\mathrm{A}=13.46(\mathrm{~Pa} \cdot \mathrm{H}) /(\mathrm{V} \cdot \mathrm{F})$ - constant, determined by the properties of the medium in which the appearance of the plasma channel (density, viscosity, etc.); U - charging voltage at the installation (V); $\mathrm{C}$ - capacity of the installation (F); L - inductance of the discharge circuit of the installation $(\mathrm{H}) ; \mathrm{T}-$ the period of oscillation of the discharge current (determined by the current waveforms) (ISS). The table presents the generalized results of calculations and experiments.

Table - results of the evaluation of the amplitude of impulse pressure

\begin{tabular}{|c|c|c|c|c|c|c|c|c|c|c|}
\hline$N$ & $j, \mathrm{ps}$ & $\begin{array}{c}U, \\
\mathrm{kV}\end{array}$ & $L, \mu \mathrm{H}$ & $\begin{array}{c}C, \\
\mu \mathrm{F}\end{array}$ & $A,(\mathrm{~Pa} \cdot \mathrm{H}) /(\mathrm{V} \cdot \mathrm{F})$ & $T, \mu \mathrm{c}$ & $t, \mu \mathrm{c}$ & $P_{\mathrm{m}}, \mathrm{MPa}$ & $\Delta r_{\text {avg }}, \mathrm{mm}$ & $U_{\text {rmsavg }}$ \\
\hline 1 & 10 & 21 & 5,5 & 30 & 13,46 & 18 & 11,64 & 119,85 & 0,00 & 2,5 \\
\hline 2 & 10 & 23 & 5,5 & 30 & 13,46 & 30 & 11,64 & 317,80 & 0,25 & 3,5 \\
\hline 3 & 10 & 24 & 5,5 & 30 & 13,46 & 37 & 11,64 & 382,29 & 0,50 & 4 \\
\hline 4 & 10 & 25 & 5,5 & 30 & 13,46 & 40 & 11,64 & 413,72 & 0,75 & 5,5 \\
\hline 5 & 10 & 28 & 5,5 & 30 & 13,46 & 45 & 11,64 & 485,57 & разрыв & \\
\hline
\end{tabular}

According to the results of processing more than 40 waveform, the dependences of the EMF from the BJ for each experiment (for each experiment series in Fig. 10, depending on the pressure amplitude Pm in Fig. 11 and the average absolute increment of the radius of the steel tube $\Delta \mathrm{r}_{\text {avg }}$ in Fig. 12) were developed. In the table, the parameter " $j$ " indicates the number of series in the experiment.

In Fig. 9, 10, 11 and 12 indices "+", "-", "avg" show $\mathrm{U}_{\text {rms }}$ built for Fig. 7 and 8 for the values respectively above the axis " 0 ", below the axis " 0 " and their average value, with the index "in" - the value for the sample before the impact of the pulse pressure on it.

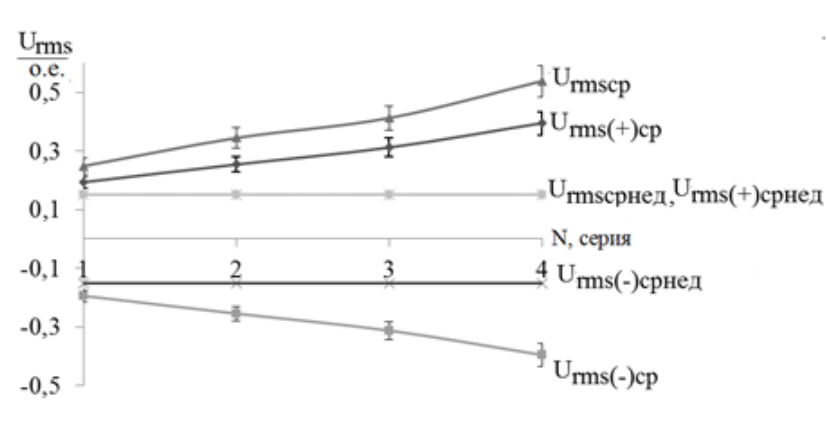

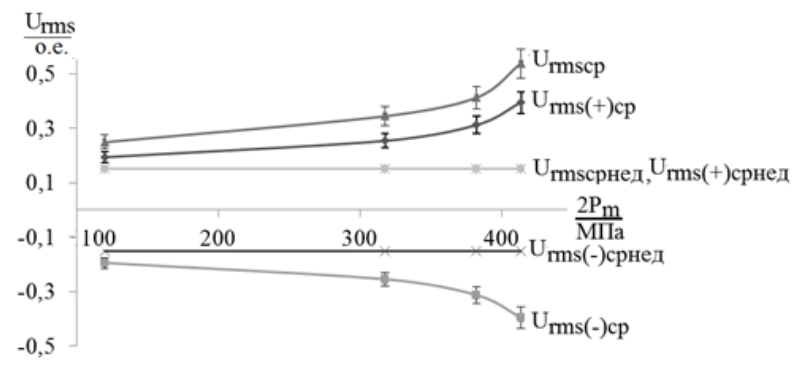

Fig. 11 - Dependence Urms=f(Pm)

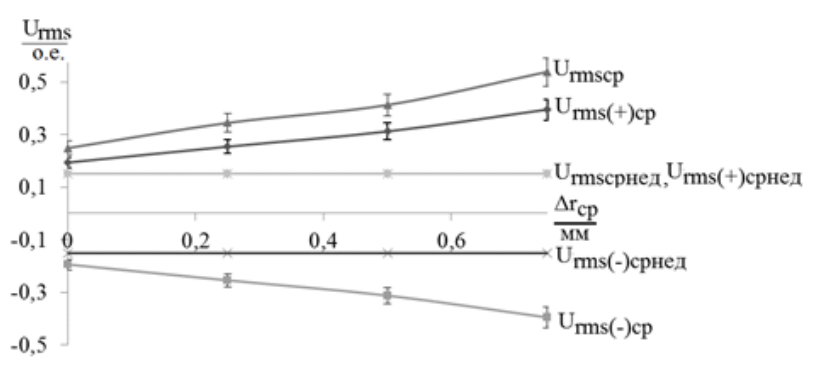

Fig. $12-$ Dependence Urms $=\left(\Delta r_{\text {avg }}\right)$

Fig. $10-$ Dependence Urms $=\mathrm{f}(\mathrm{N})$ 


\section{Conclusions}

The analysis of the experimental data shows that the control method based on the BE is sufficiently sensitive to the level of internal residual stresses in the steel tubular parts subjected to the action of pressure pulses. In particular, the presence of internal stresses on the EMF from the BJ for the case of no visible plastic deformations (sample of series of experiments $\mathrm{N}=1$ ). It was shown that there is a relationship between the growth of the impacting pressure and EMF from the BJ, while it is typical for tensile strain. At the same time, as shown by the analysis of sources [11-18], the presence of increasing of EMF from the BJ may indicate the presence of defects and the higher they are, the probability of defects is higher. The obtained experimental results confirm these conclusions. Thus, it is possible to make a conclusion about the possibility of using the EB method to control the stress-strain state of the connection of tubular parts after the impact of pulse pressure on them.

\section{References}

1. Chadwick M.D., Howd D., Wildsmith G. Explosive welding of tubes and tube - plates. British Welding Journal. 1968, v.15, No. 10, pp. 440-492.

2. Williams P.S.G. Welding Parameters for Explosive Cladding of Non-Ferrous tubes. - Proceedings of the conference "Welding and fabrica-tion of non ferrous metals", Cambridge, the Welding Institute, 1972, pp. 108121.

3. K. Thyboe Christensen et al. Explosive Welding of Tubes and Tubeplates // Journal of Metal Construction and British Welding Institute. 1973, No. 11, p. 412.

4. Bahrani A.S., Halliburton R.F., Crossland B. Parallel technique of tube to tubeplate welding applied to plugging of heat exchangers. Interna-tional Journal of Pressure Vessels and Piping. 1973, v. 1, No. 1, pp. 17-35.

5. Hardwick R. Methods for Fabricating and Plugging of Tube to Tubesheet Joints by Explosion Weldings. Welding Journal, No. 4, 1975, pp. 238-244.

6. Bazhan P.I., Kanevets G.I., Seliverstov V.M. Handbook of heat ex-changers. - M.: Mechanical Engineering, 1989 .-- 369 p. : ill.

7. GOST R 52630-12 Welded steel vessels and apparatus. General specifications. - Enter. 2013-04-01. M .: Standartinform, 2013 .-- 87 p.

8. Kolmakov V.P., Dmitriev V.G., Chebotnyagin L.M., Potapov V.V., Suslov K.V. Connection of tubular parts with an electric explosion of a conductor: monograph Irkutsk: Publishing House of ISTU, 2011. - 152 p.

9. Chebotnyagin L.M., Potapov V.V., Lopatin V.V. Kinetics of Defor-mation of Alloys by Pulsed Pressure of an Electric Discharge // Russian Physics Journal. 2015, Vol. 58, No. 1, pp. 56-62, DOI: 10.1007 / s11182-0150462-4

10. Kolmakov V.P., Grechneva M.V., Potapov V.V., Chebotnyagin L.M. Improving the quality of the tubetube plate welded joint in welding with the energy of electrical explosion of a conductor // Welding International. 2015. Vol. 29, Issue 8, pp. 633-638. DOI:

\subsection{0 / 09507116.2014 .960699}

11. Lopatin M.V. Non-destructive testing methods for residual stresses in metal structures (brief review) // Welding in Siberia. - 1999, December (No. 3), S. 64-67. 12. Nikolaeva EP, Gridasova EV, Gerasimov VV The use of X-ray dif-fraction analysis and Barkhausen noise for the study of structural steel 30KhGSA after shot-blasting // Bulletin of the Samara Scientific Center of the Russian Academy of Sciences. Mechanics and mechanical engineer-ing. - 2015, T17, No. 2, S. 125-132.

13. Lomaev G.V., Malyshev B.C., Degtyarev A.P. A review of the ap-plication of the Barkhausen effect in nondestructive testing // Defectos-copy. - 1984, No. 3, S. 5470.

14. Barton J.R. Residual stress in gas turbine engine components from Barkhausen noise analysis / J.R. Barton, I.H. Kuzenberger // Trans. Adme, Ser A. - 1974, No. 4, pp. 23-33.

15. Maksimov I.L. On the possibility of controlling mechanical stresses in pipelines by the method of magnetic noise // Oil industry, oil transporta-tion and storage. - 1981, No. 5, S. 2-4.

16. Karjaiainen L-P., Moilanen M. Detection of plactic deformation during fatigue of mild steel by the measurement of Barkhausen noise // NDT International. 1979, v. 12, No. 2, pp. 51-55.

17. Karjalainen L-P., Moilanen M., Bautiaho B. Influence of tensile and Cyclic loading upon Barkhausen noise in a mild steel // Materials Eval-uation. - 1979, v. 37, No. 9, pp. 43-51.

18. Filinov, V.V. Monitoring the stress state of pipelines by magnetic parameters of metal / V.V. Filinov, A.N. Kuznetsov, P.G. Arakelov // Defec-toscopy. - 2017. - No. 1. - S. 41-50.

19. Mazurovsky, B.Ya. Electrohydropulse press fitting of pipes in tube sheets of heat exchangers: monograph. Kiev: Naukova Dumka, 1980 - 172 p. : ill.

20. Nugolnykh K.A., Roy N.A. Electric discharges in water. - M.: Pub-lishing House "Science", 1971. - $155 \mathrm{~s}$ 21. The Hermit, E.I. Statistical methods for the analysis and pro-cessing of observations: a monograph. - M .: Nauka, 1968 .-- 288 p.

22. Chebotnyagin L.M. Connection of tubular parts by pulsed pres-sure of an expanding plasma channel of an electric discharge: dis. ... cand. tech. Sciences: 05.14.12: protected 26.11.2014: approved. 04/06/2015 / Chebotnyagin Leonid Mikhailovich. - Tomsk, 2014 .-$137 \mathrm{~s}$. 